\title{
Metal injection moulding of superelastic TiNi parts
}

\author{
J.-E. Bidaux ${ }^{1}, \mathrm{a}^{*}$, A. Amherd Hidalgo ${ }^{1}$, H. Girard ${ }^{1}$, M. Rodriguez-Arbaizar ${ }^{1}$, \\ L. Reynard ${ }^{1}$, J. Chevallier², F. Aeby ${ }^{2}$, J.-C. Giachetto ${ }^{2}$, E. Carreño-Morelli ${ }^{1}$ \\ ${ }^{1}$ University of Applied Sciences and Arts Western Switzerland, Rte du Rawyl 47, \\ 1950 Sion, Switzerland
}

${ }^{2}$ Dentsply Maillefer, Ch. du Verger 3, 1338 Ballaigues, Switzerland

ajeric.bidaux@hevs.ch

Keywords: Metal Injection Moulding, Titanium-Nickel alloys, Superelasticity, Dental Applications

\begin{abstract}
TiNi shape-memory properties are successfully used today for the fabrication of various technical devices. The limited machinability and high cost of TiNi encourage the use of near-net shape production techniques such as metal injection moulding. In this work TiNi alloys tensile test specimens are produced by metal injection moulding from pre-alloyed powders. A binder based on a mixture of polyethylene, paraffin wax and stearic acid is used. Parts with a density of about $96.6 \%$ of theoretical density are obtained. Scanning electron microscopy coupled with EDX measurements reveals a microstructure consisting of a TiNi matrix with small $\mathrm{Ti}_{4} \mathrm{Ni}_{2} \mathrm{O}_{\mathrm{x}}$ and $\mathrm{TiC}$ inclusions. DSC and $\mathrm{X}$-ray diffraction observations indicate the presence of additional $\mathrm{Ni}_{4} \mathrm{Ti}_{3}$ precipitates. The parts exhibit full superelasticity at room temperature even for strains of up to $4 \%$, without the need for additional thermal post-treatments. Ultimate tensile strengths up to $980 \mathrm{MPa}$ are obtained.
\end{abstract}

\section{Introduction}

Discovered in 1962 by Buehler and Wang, TiNi alloys remain today the commercially most important shape-memory alloys [1,2]. The unique properties of TiNi alloys, shape-memory and superelasticity are currently applied in various domains, such as aerospace, biomedical, robotics, automotive, etc. Today TiNi raw products and components are mostly produced by the ingot metallurgy route, i.e. typically melt casting, hot and cold working, thermal treatments and machining. However, machining of TiNi is difficult and is associated with extensive tool wear. Cold working is accompanied by high strain hardening, leading to expensive intermediate thermal treatments. Metal injection moulding (MIM) is currently investigated as an alternative for the fabrication of TiNi components [3-6] because it allows manufacturing net-shape components in large series.

Attempts to produce TiNi by MIM were performed by the elemental powders route $[3,6-8]$. The shape-memory effect was demonstrated on tensile test samples and plates subjected to bending $[3,6]$. However reactive sintering leads to undesired secondary phases and relatively low densities, in the range of 55-92\%, leading presumably to poor mechanical properties although these were not reported. However many applications of $\mathrm{TiNi}$, in particularly those using the superelasticity require good mechanical properties. To fulfil this requirement, extensive work was oriented towards the pre-alloyed powders method [4,5,9-11]. Tensile test samples, bone staples, pipe connectors were fabricated by metal injection moulding from pre-alloyed powders [10,12]. Densities ranging from 90 to $97 \%$ and tensile strengths of up to $1000 \mathrm{MPa}$ were reported [5,11]. Superelasticity was demonstrated for deformations up to $2 \%$. Among the main challenges of MIM of TiNi are the poor sintering activity and the high reactivity of TiNi powder to oxygen and carbon [11]. Even if the impurity content of MIM TiNi parts does not meet ASTM F2063 standard, ductile behaviour could be obtained starting from particularly high purity powders $[11,13]$.

In the present work, the production by MIM of superelastic TiNi is investigated. In the perspective of minimizing cost, the work focuses on the as-sintered properties i.e. without any additional operations (such as solution or ageing treatments for example). Fine pre-alloyed powders are used in order to achieve a density as high as possible, with the goal of obtaining reliable 
mechanical properties. Superelastic properties are measured on the as-sintered parts without any finishing operation.

\section{Experimental}

A TiNi SE 508 alloy rod (nominal composition $50.8 \mathrm{at} \% \mathrm{Ni}$, hot rolled) was purchased from SAES Smart Materials (NY, USA) to serve as starting material. The transformation temperatures of the rod were measured using a Mettler Toledo DSC823e calorimeter. Heating and cooling rates of $10^{\circ} \mathrm{C} / \mathrm{min}$ were used. The transformation temperatures were identified by using the tangent method according to ASTM F $2004-05$ (Table 1). $\mathrm{M}_{\mathrm{s}}, \mathrm{M}_{\mathrm{f}}, \mathrm{A}_{\mathrm{s}}, \mathrm{A}_{\mathrm{f}}$ indicate the martensite start, martensite finish, austenite start and austenite finish temperatures respectively. The $A_{f}$ temperature is $18.5^{\circ} \mathrm{C}$, which is below room temperature, as expected for a nominally superelastic material.

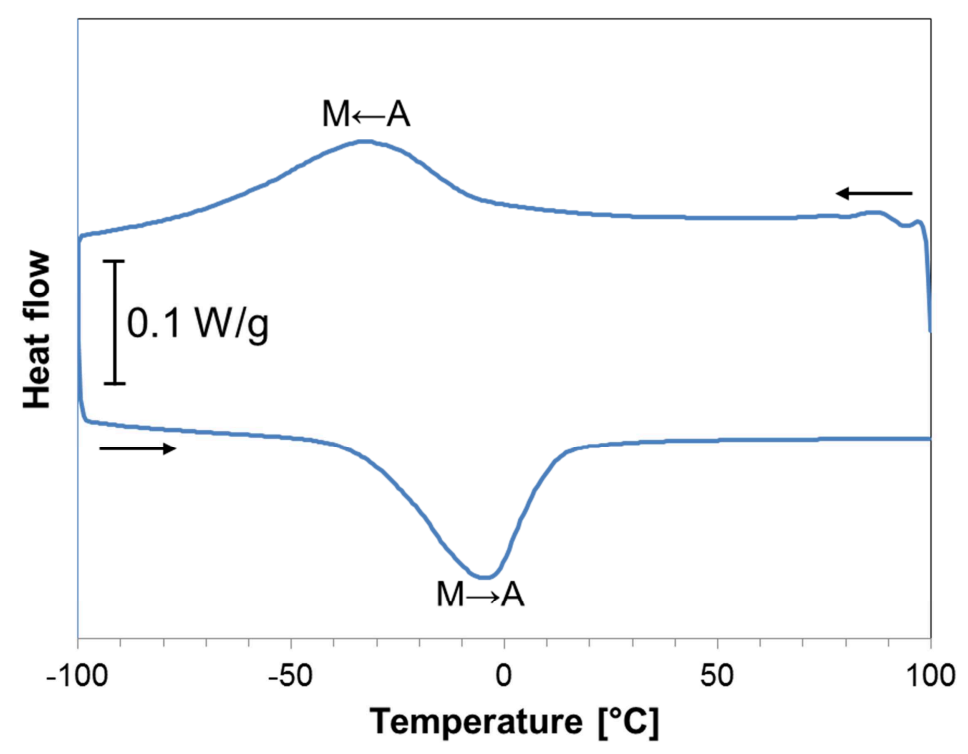

Fig. 1. TiNi rod and related DSC curve showing martensitic transformation

Table 1. Transformation temperatures of the TiNi rod as measured by DSC

\begin{tabular}{lcccccc}
\hline Sample & $\mathbf{M}_{\mathbf{s}}\left[{ }^{\circ} \mathbf{C}\right]$ & $\mathbf{M}_{\mathbf{p}}\left[{ }^{\circ} \mathbf{C}\right]$ & $\mathbf{M}_{\mathbf{f}}\left[{ }^{\circ} \mathbf{C}\right]$ & $\mathbf{A}_{\mathbf{s}}\left[{ }^{\circ} \mathbf{C}\right]$ & $\mathbf{A}_{\mathbf{p}}\left[{ }^{\circ} \mathbf{C}\right]$ & $\mathbf{A}_{\mathbf{f}}\left[{ }^{\circ} \mathbf{C}\right]$ \\
\hline Starting TiNi rod & 1.2 & -33.3 & -77.9 & -34.2 & -5.1 & 18.5 \\
\hline
\end{tabular}

The rod was molten and gaz atomized by the Nanoval process (Nanoval GmbH, Germany) to produce spherical pre-alloyed powder. The powder was sieved by the manufacturer and supplied in batches of different mesh-size fractions. In the present study, only the fraction below $20 \mu \mathrm{m}$ was used. Fig. 2 shows a scanning electron micrograph of a sample of powder. The scanning electron microscope was a LEO 1525 equipped with energy dispersive X-ray analysis (EDX)).

The Nanoval process was chosen because of its high yield for fine powder: $53 \%$ of the total powder mass was below $20 \mu \mathrm{m}$. Figure 3 shows the particle size distribution as determined by laser diffractometry using a Malvern Mastersizer 2000 apparatus. From the size distribution the following characteristic diameters were inferred: Dv10=3.7 $\mu \mathrm{m}, \mathrm{Dv} 50=10.3 \mu \mathrm{m}$ and Dv90=21.5 $\mu \mathrm{m}$. 


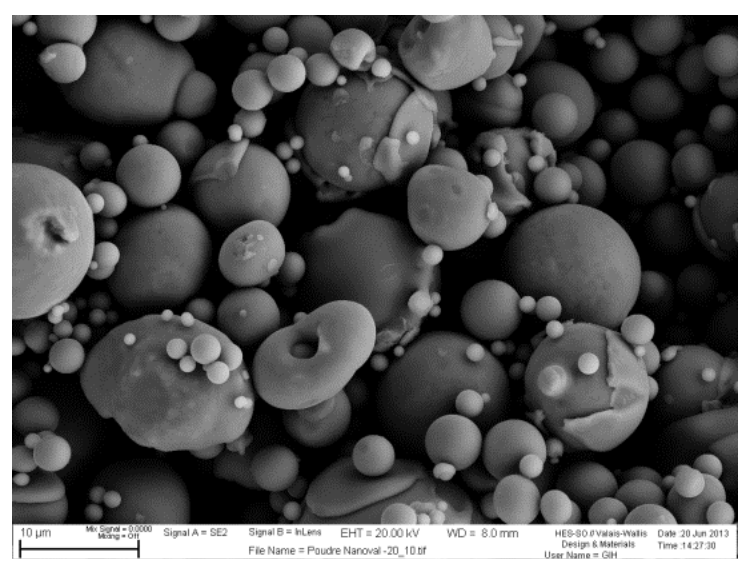

Fig. 2. SEM picture of the gaz-atomized TiNi prealloyed powder

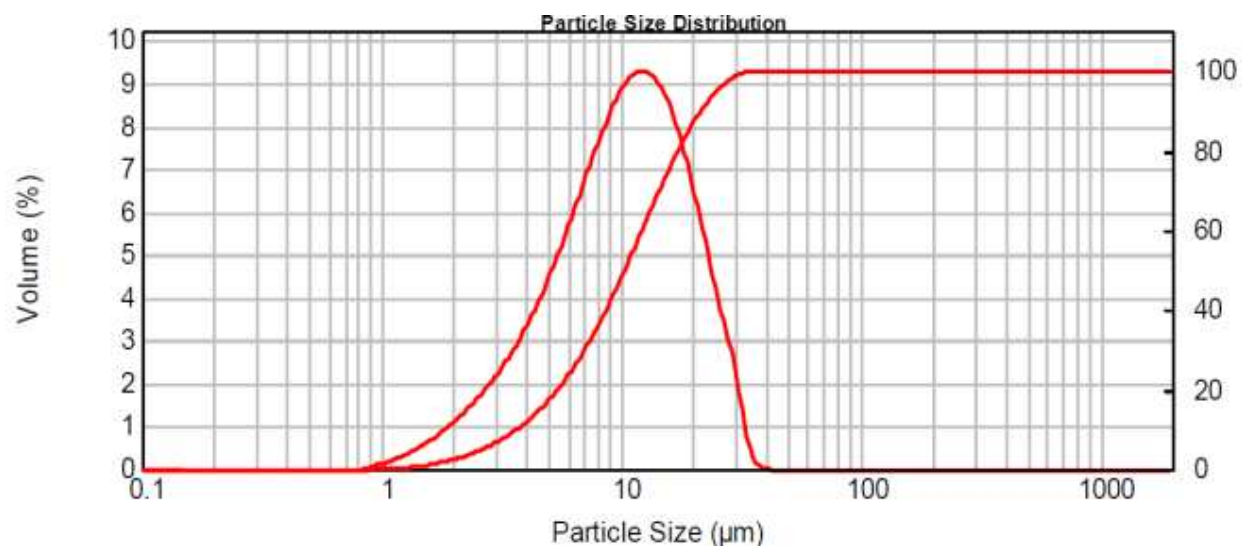

Fig. 3. Particle size distribution of the TiNi prealloyed powder

The powder was mixed with a multi-component polymer binder in a Coperion Werner \& Pfleiderer double sigma mixer to obtain a feedstock suitable for injection moulding. The binder was composed of 55wt\% paraffin wax (Sigma Aldrich $\mathrm{GmbH}$, Buchs, Switzerland), $35 \mathrm{wt} \%$ low density polyethylene (LDPE Riblene MP30, Polimeri Europa, Italy) and 10wt\% stearic acid (Sigma Aldrich $\mathrm{GmbH}$, Buchs, Switzerland). Mixing was performed for $4 \mathrm{~h}$ at $145^{\circ} \mathrm{C}$ under argon gas protection. Feedstock granules were obtained by cooling down and crushing the mixture by slow shearing. The uniformity and homogenity of the granules were further enhanced by extruding the feedstock using an Arburg $221 \mathrm{~K}$ injection moulding machine as an extruder. Tensile test specimens were injection moulded in the same machine, in a thermalized two half mold. The dimensions of the cavity mould are shown in Fig. 4.
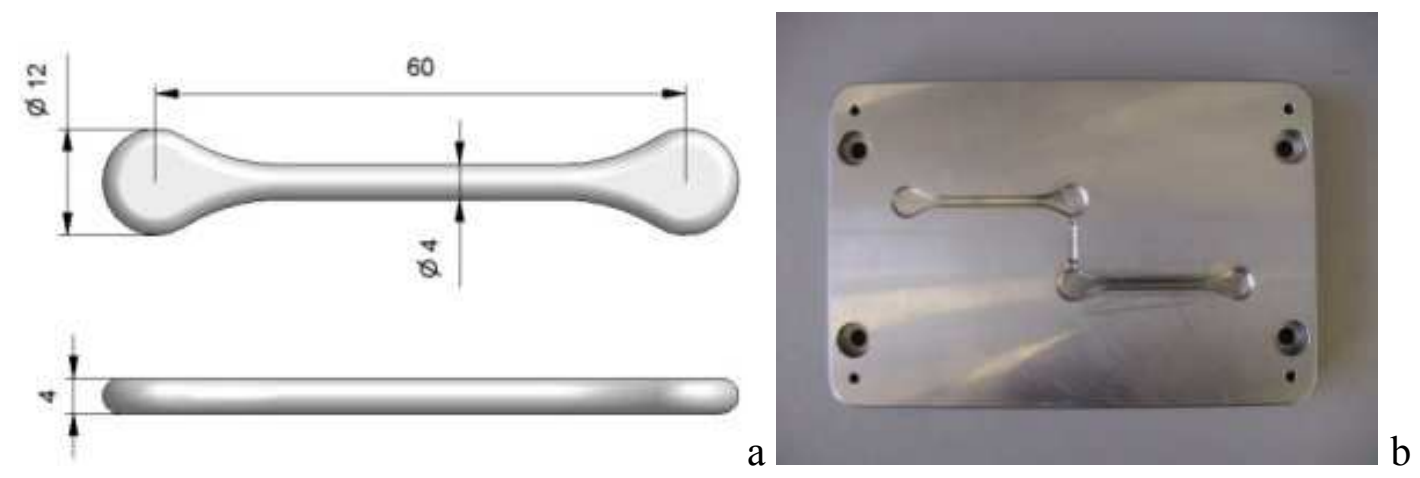

Fig. 4. (a) Tensile test sample dimensions and (b) mould half showing mould cavities 
Binder removal was accomplished by solvent debinding in heptane for $24 \mathrm{~h}$ at $50^{\circ} \mathrm{C}$. The parts were thermally debinded and sintered in the same thermal cycle, as shown in Figure 5, in a Nabertherm VHT08-16MO MIM furnace.

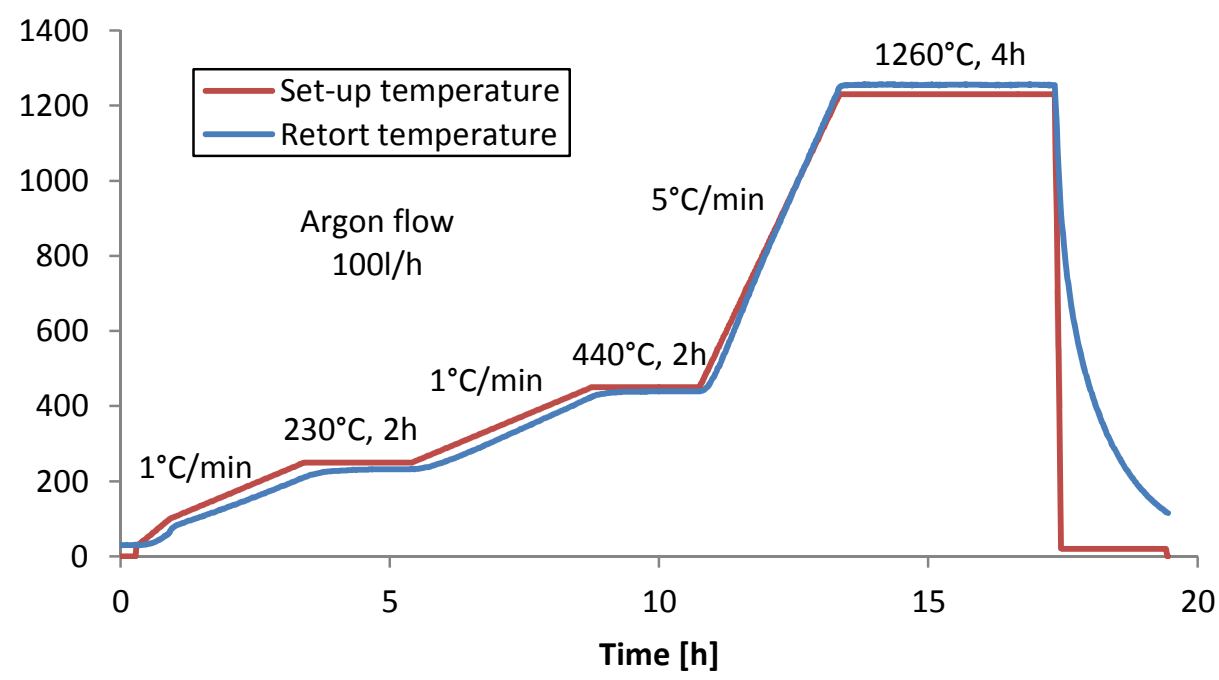

Fig. 5. Thermal debinding and sintering cycle for MIM TiNi samples

The samples were placed on an yttria coated alumina sintering setter to minimize reactions with the support. Thermal debinding was performed in two steps, first for $2 \mathrm{~h}$ at $230^{\circ} \mathrm{C}$, then $2 \mathrm{~h}$ at $440^{\circ} \mathrm{C}$. Sintering was accomplished for $4 \mathrm{~h}$ at $1260^{\circ} \mathrm{C}$. X-ray diffraction patterns were recorded using an X'pert Pro PANalytical X-ray diffractometer (B.V., Almelo, The Netherlands). Tensile tests were performed using a Zwick 1475 machine equipped with extensometers with a gauge length of $16 \mathrm{~mm}$. Test parameters were set according to standard DIN EN ISO 6892-1 method B. The test sequence was the following: specimens were first loaded to $4 \%$ strain, then unloaded to $10 \mathrm{MPa}$ in such a way as to obtain a superelastic loop and finally loaded to failure. All tensile tests were performed on the neat specimens, i.e. without any finishing operation. The density of the sintered parts was measured by the Archimedes method using isopropyl alcohol as the immersion medium. The specimen microstructure was investigated using a LEO 1525 scanning electron microscope equipped with energy dispersive X-ray analysis (EDX). The interstitial content in both base powder and sintered parts was measured by conventional melt extraction using a LECO TCH 600 apparatus for nitrogen, oxygen and hydrogen and a LECO CS 230 for carbon.

\section{Results}

Fig. 6 shows both green and sintered parts. Good shape retention is observed. The average axial shrinkage between green and sintered parts is about $14.1 \%$. The density of the sintered part is 6.23 $\mathrm{g} / \mathrm{cm}^{3}$ i.e. approximately $96.6 \%$ of the theoretical density $\left(6.45 \mathrm{~g} / \mathrm{cm}^{3}[11]\right)$.

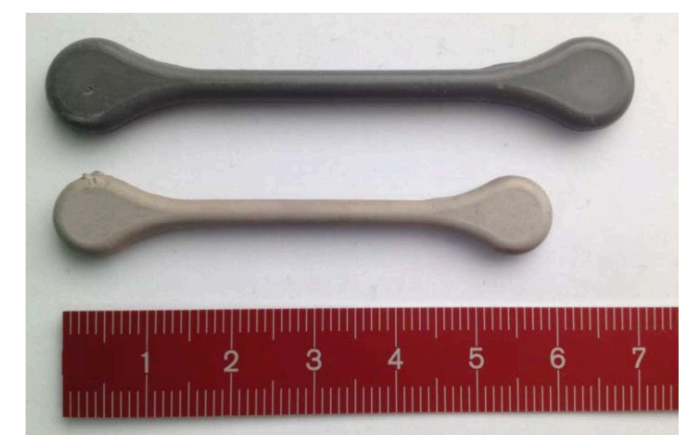

Fig. 6. Green and sintered MIM TiNi parts 
The interstitial contents in both base powder and sintered MIM parts are shown in Table 2 and compared to the ASTM F2063 standard for wrought TiNi for medical devices and surgical implants.

Table 2. Interstitial content of base powder and MIM specimen

\begin{tabular}{lccc}
\hline \multicolumn{1}{c}{ Sample } & O [wt\%] & N [wt\%] & C [wt\%] \\
\hline TiNi powder & $0.123 \pm 0.012$ & $0.007 \pm 0.007$ & $0.086 \pm 0.001$ \\
MIM TiNi & $0.130 \pm 0.006$ & $0.006 \pm 0.001$ & $0.115 \pm 0.005$ \\
ASTM F2063 & \multicolumn{2}{c}{0.05} & 0.05 \\
\hline
\end{tabular}

Carbon and oxygen are the most significant impurities in both TiNi powder and sintered specimens (Table 2). The carbon uptake during processing can be explained by the contact between the powder and the organic binder or by an incomplete debinding. The small oxygen uptake can be attributed to reactions with the residual oxygen present in the sintering atmosphere [11]. Another source of oxygen pickup could be a reaction with residual stearic acid, uncompletely removed during solvent debinding. In any case, the uptake is very low considering the error of the measured values. The impurity content of the MIM TiNi does not meet the ASTM standard. However it was already the case of the base powder. As a matter of fact, the ASTM standard for TiNi is much more demanding than that of most titanium alloys. The reason lies in the fact that oxygen, carbon and nitrogen are almost insoluble in TiNi. Oxygen contents higher than 0.045 at $\%$ thus lead to the formation of the $\mathrm{Ti}_{4} \mathrm{Ni}_{2} \mathrm{O}_{x}$ oxides, giving rise to embrittlement of the alloy $[14,15]$.

A series of micrographs with different magnifications of the polished surface of an as-sintered sample is shown in Fig. 7. The observed area is located at the onset of the dog-bone specimen head (Fig. 7a). The porosity is uniformly distributed. Most of pores are below $20 \mu \mathrm{m}$ (Fig. 7b). The matrix was identified by EDX as TiNi. The slight excess in Ni relative to $\mathrm{Ti}$ is consistent with the nominal 50.8at\% composition (Table 3). The small light grey inclusions are identified as $\mathrm{Ti}_{4} \mathrm{Ni}_{2} \mathrm{O}_{\mathrm{x}}$ oxides (Spectrum 1, Fig. 7), which are very common in TiNi alloys. It is well known from the literature that the oxygen exceeding the solubility limit is absorbed in the $\mathrm{Ti}_{4} \mathrm{Ni}_{2} \mathrm{O}_{\mathrm{x}}$ phase [14]. Thus the $\mathrm{Ti}_{4} \mathrm{Ni}_{2} \mathrm{O}_{\mathrm{x}}$ oxides are expected, owing to the above mentioned high oxygen content. Apart from the light grey inclusions, smaller dark grey inclusions are visible, which can be identified as TiC. The fact that the $\mathrm{Ti} / \mathrm{C}$ ratio differs from stoichiometry can be explained by the very small size of the carbides (in general below $5 \mu \mathrm{m}$ ) and the unavoidable contribution of $\mathrm{Ti}$ and $\mathrm{Ni}$ from the surrounding matrix to the measured EDX spectra. The size of the oxides and carbides is below 30 $\mu \mathrm{m}$, which is the limit allowed by the ASTM standard.

Fig. 8 shows the DSC curve of the as-sintered part. Compared to the DSC of the original rod (Fig.1), the peaks are much weaker and broader. In addition, the transformation occurs in two steps: on cooling $\mathrm{A} \rightarrow \mathrm{R}$ and $\mathrm{R} \rightarrow \mathrm{M}$ and on heating $\mathrm{M} \rightarrow \mathrm{R}$ and $\mathrm{R} \rightarrow \mathrm{A}$, where $\mathrm{R}$ indicates the intermediate $\mathrm{R}$ phase transformation. The $\mathrm{R}$ phase certainly results from the presence of precipitates in the assintered part. TiNi alloys with $\mathrm{Ni}$ contents exceeding $50.5 \mathrm{at} \%$ decompose when slowly cooled from high temperature or during aging below about $700^{\circ} \mathrm{C}$ [14]. The first stage of precipitation is the formation of the $\mathrm{Ni}_{4} \mathrm{Ti}_{3}$ phase. At the concentration $50.8 \mathrm{at} \% \mathrm{Ni}$, the precipitation rate is the highest around $400^{\circ} \mathrm{C}$ [15]. During furnace cooling this critical temperature region is probably passed through slowly enough to allow precipitation. The presence of a fine distribution of coherent $\mathrm{Ni}_{4} \mathrm{Ti}_{3}$ precipitates is known to be one of the factors at the origin of the presence of the $\mathrm{R}$ phase in TiNi alloys [17]. 


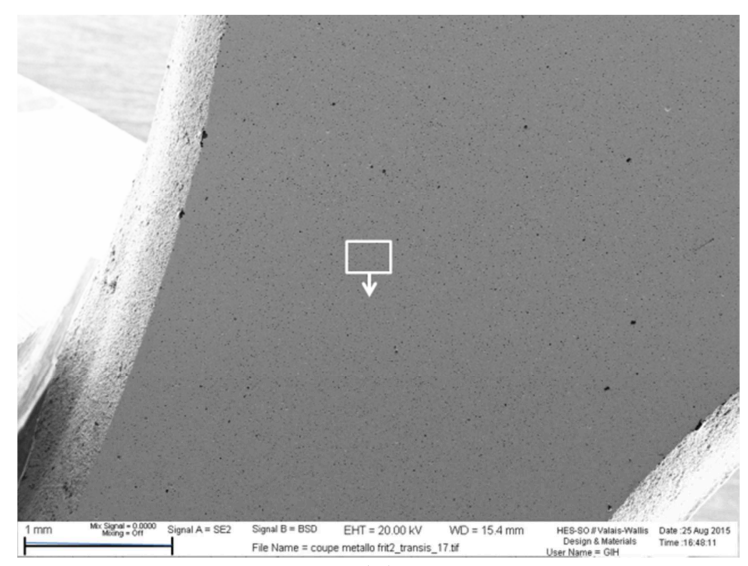

(a)

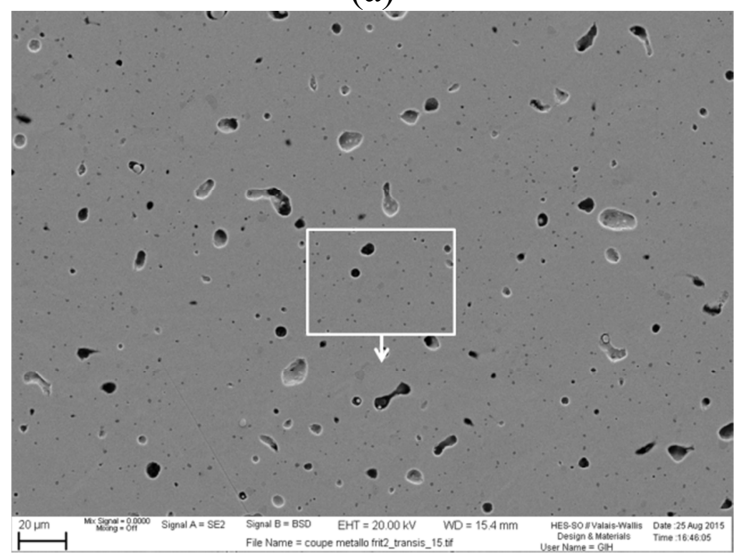

(b)

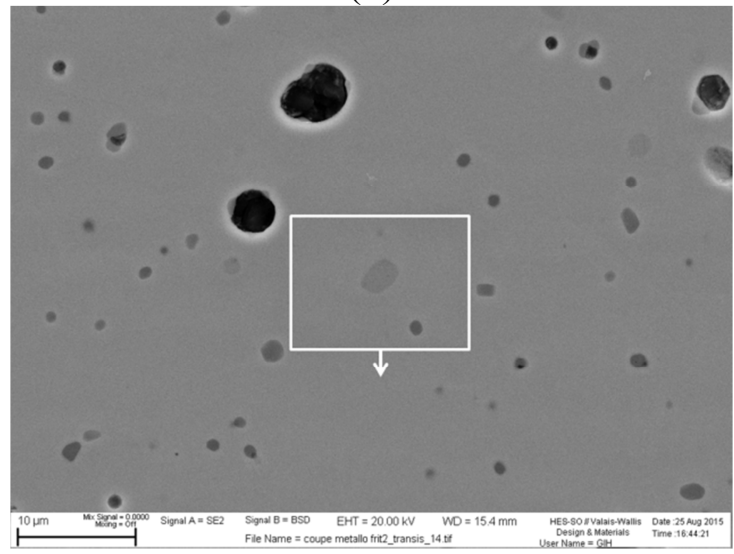

(c)

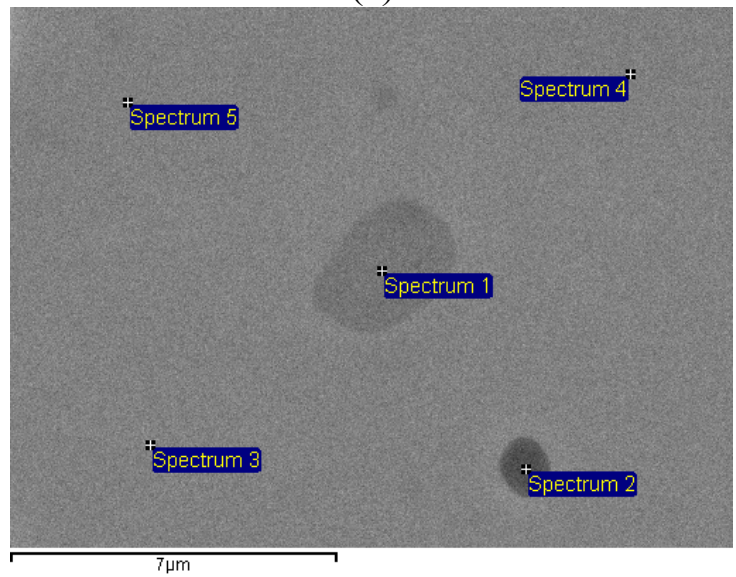

(d)

Fig. 7. SEM observation of MIM TiNi at increasing magnification from (a) to (d) 
Table 3. Local compositions as measured by EDX

\begin{tabular}{lcccc}
\hline Spectrum & $\mathbf{C}[\mathbf{a t} \%]$ & $\mathbf{T i}[\mathbf{a t} \%]$ & $\mathbf{N i}[\mathbf{a t} \%]$ & Phase \\
\hline Spectrum 1 & - & 66.4 & 33.6 & $\mathrm{Ti}_{4} \mathrm{Ni}_{2} \mathrm{O}_{\mathrm{x}}$ \\
Spectrum 2 & 32.2 & 45.9 & 21.9 & $\mathrm{TiC}$ \\
Spectrum 3 & - & 48.8 & 51.2 & $\mathrm{TiNi}$ \\
Spectrum 4 & - & 49.2 & 50.8 & $\mathrm{TiNi}$ \\
Spectrum 5 & - & 49.1 & 50.9 & $\mathrm{TiNi}$ \\
\hline
\end{tabular}

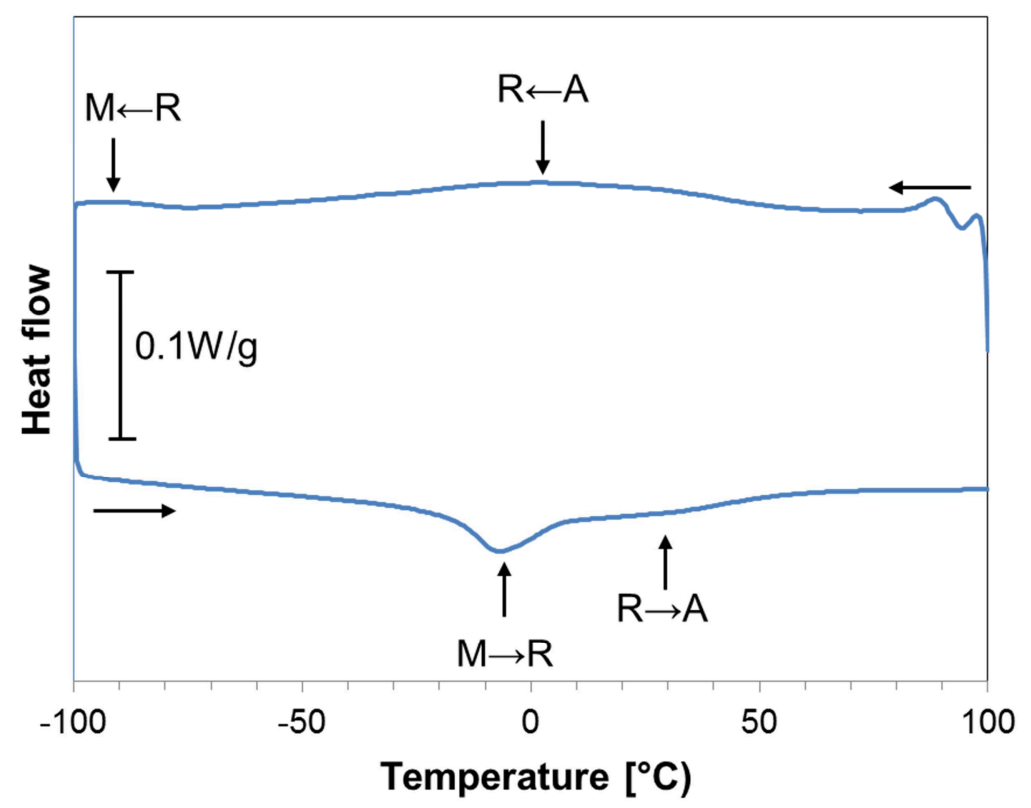

Fig. 8. DSC curve of MIM TiNi

In an attempt to confirm the presence of both the $\mathrm{Ni}_{4} \mathrm{Ti}_{3}$ precipitates and the R-phase, X-ray diffraction measurements were performed. In Fig. 9, the X-ray diffraction pattern of the as-sintered specimen is compared to that of the starting pre-alloyed powder. No evidence of the presence of the R-phase in the as-sintered specimen could be found. All peaks can be indexed as austenitic B2 TiNi. However, the R-phase is not easy to distinguish from the austenite. The lattice distortion between austenite and R-phase in Ti-Ni is small, less than one degree [18]. In X-ray diffraction, the R-phase is characterized by a splitting of the main austenitic B2 peak into two sub-peaks. The distance between the sub-peaks is of the order of only a fraction of a degree. The resolution of the present measurements was thus probably not sufficient for the splitting to be resolved.

In contrast, evidence is found for the presence of the $\mathrm{Ni}_{4} \mathrm{Ti}_{3}$ precipitates. In Fig. 9, a shoulder close to the main TiNi peak is observed, which indicates the first stage of the formation $\mathrm{Ni}_{4} \mathrm{Ti}_{3}$ precipitates [12]. Indeed the peak is not fully developed, as after standard ageing treatments [17]. Finally, oxides and carbides previously observed by SEM were definitely in too small quantities to be detected.

A typical result of a tensile test for an as-sintered part is shown in Fig. 10. The sample was initially loaded up to $4 \%$ strain and then completely unloaded. The residual strain after unloading is less than $0.02 \%$. A clear plateau upon loading and unloading is observed with a stress hysteresis of about $200 \mathrm{MPa}$. The sample was finally loaded to rupture, which occurs at about $980 \mathrm{MPa}$. The sample broke in a brittle manner without apparent sign of plastic deformation. A series of measurements gave ultimate tensile strengths values in the range of $660-980 \mathrm{MPa}$. 


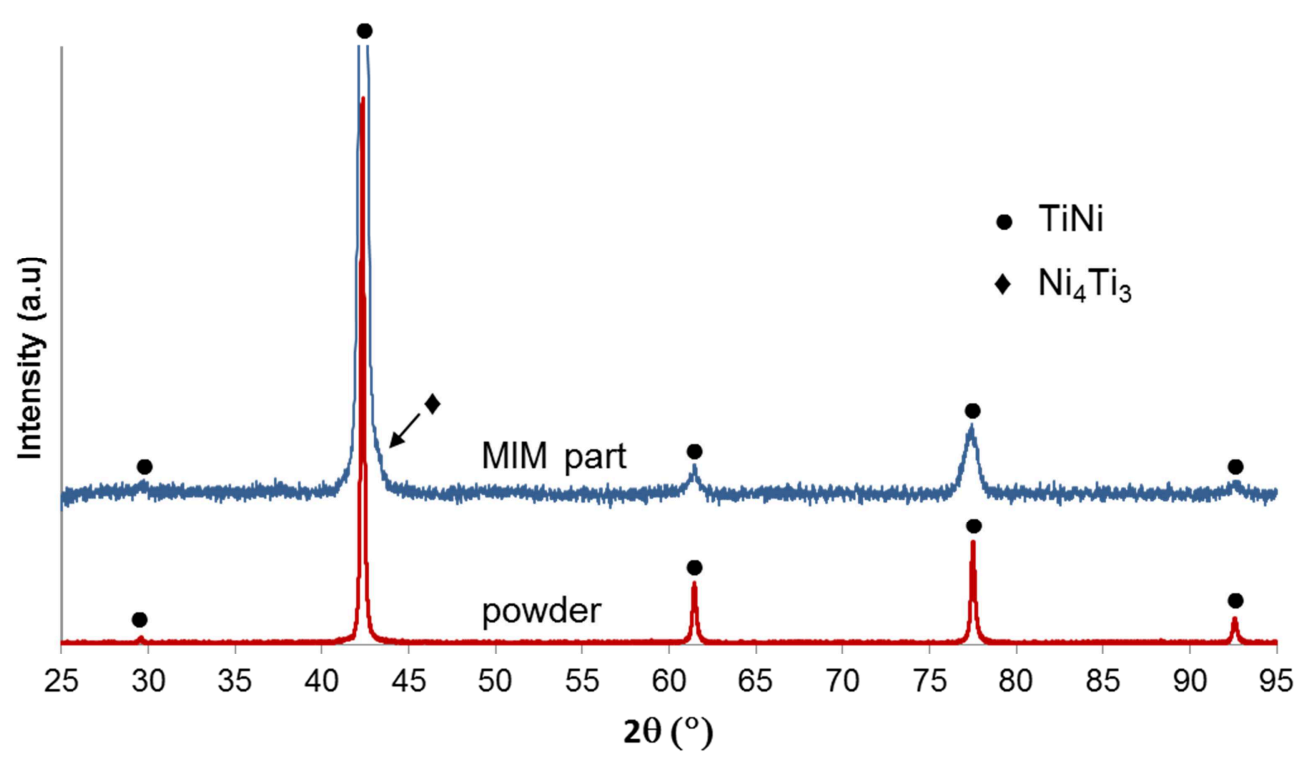

Fig. 9. X-ray diffraction patterns of MIM TiNi and starting TiNi powder

The fact that the specimen is fully superelastic at room temperature is nevertheless surprising. As indicated by the DSC data (see Fig. 8), the MIM specimen is in the R phase at room temperature. Accordingly, a residual strain (pseudoplastic strain), resulting from the reorientation of the R-phase variants (up to $0.8 \%$ depending on the temperature) should appear after complete unloading [19]. A possible reason for the absence of a residual strain might be the heterogeneity of the microstructure. The material might actually be only partially in the R-phase. The rest of the material, which we can assume austenitic and therefore superelastic, would be able to produce the necessary force to restore the original shape after unloading (bias-spring effect) in spite of the presence of the R-phase. However, this interpretation needs confirmation.

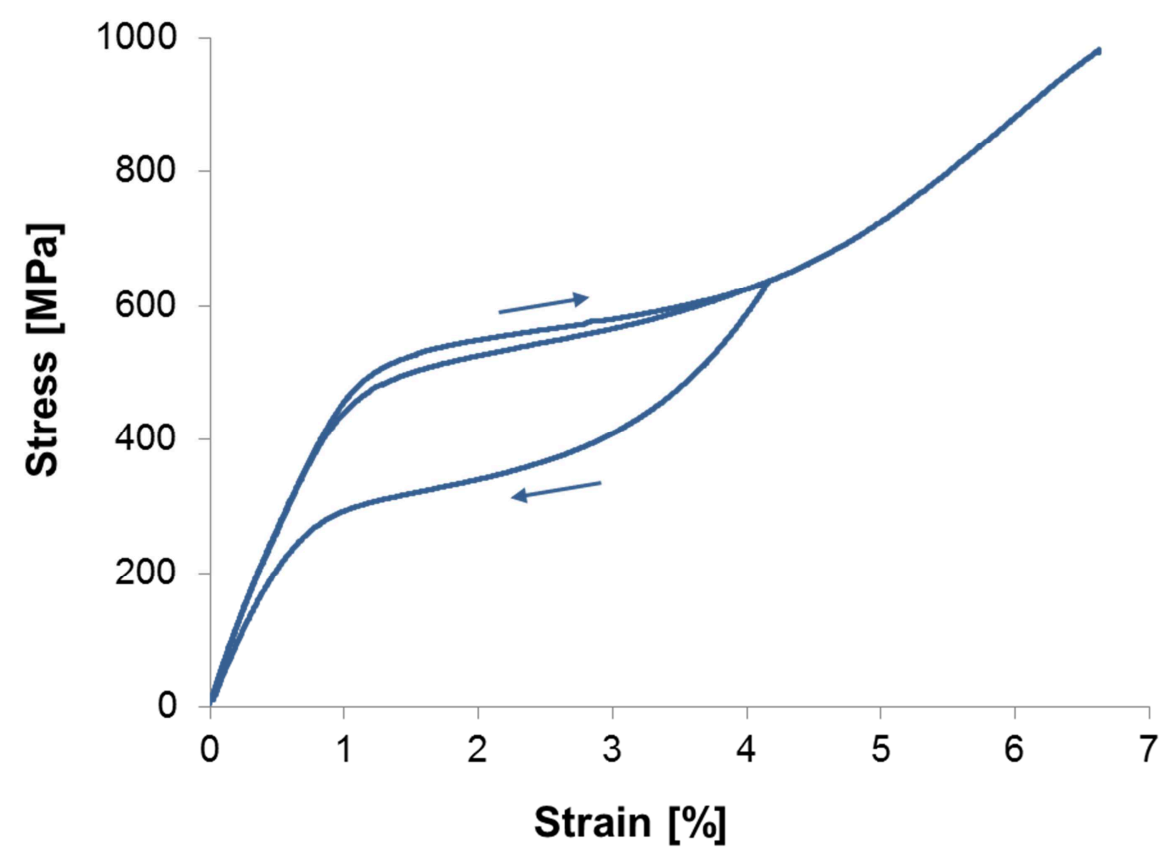

Fig. 10. Tensile test behaviour of MIM TiNi 


\section{Conclusions}

TiNi parts with densities of about $96.6 \%$ of the theoretical density have been successfully produced by metal injection moulding. SEM observations indicate that the samples consist of a TiNi matrix with small $\mathrm{Ti}_{4} \mathrm{Ni}_{2} \mathrm{O}_{\mathrm{x}}$ and $\mathrm{TiC}$ inclusions. DSC data and X-ray diffraction observations indicate the presence of $\mathrm{Ni}_{4} \mathrm{Ti}_{3}$ precipitates. The specimens exhibit a fully superelastic behaviour at room temperature with a well-defined plateau and full recoverability even for strains of up to 4\%, without the need for additional thermal post-treatments. Ultimate tensile strengths of up to $980 \mathrm{MPa}$ have been achieved.

\section{Acknowledgments}

Financial support by the Swiss Commission for Technology and Innovation (CTI) under grant CTI 14072.1 PFLS-LS is gratefully acknowledged

\section{References}

[1] K. Otsuka, T. Kakeshita, Science and technology of shape-memory alloys: New developments, MRS Bulletin (2002) 91-100

[2] K. Otsuka, X. Ren, Physical metallurgy of Ti-Ni-based shape memory alloys, Progress in Materials Science 50 (2005) 511-678

[3] A. Smolders, D. Aslanidis, A. Serneels, S. Van den Bossche, W. Vandermeulen, Manufacturing of shape memory alloys by powder metallurgy, Proc. of the First European Conf. on Shape Memory and Superelastic Technologies (SMST-99), Antwerp, Belgium (1999) 412-419

[4] M. Bram, A. Ahmad-Khanlou, A. Heckmann, B. Fuchs, H.P. Buchkremer, D. Stöver. Powder Metallurgical fabrication processes for NiTi shape memory alloy parts, Materials Science and Engineering A337 (2002) 254-263

[5] Ph. Imgrund, A. Rota, H. Schmidt. $\mu$-MIM: Making the most of NiTi, in Metal Powder Report, May 2008, 21-24

[6] J.-E. Bidaux, A. Jochem, E. Carreño-Morelli, Powder injection moulding of NiTi shape memory alloys, Powder Injection Moulding International, vol.2 №1 (2008) 59-62

[7] M. H. Ismail, R Goodall, H. A. Davies, I. Todd, Porous NiTi metal injection moulding/sintering of elemental powders: Effect of sintering temperature, Materials Letters 70 (2012) 142-145

[8] G. Chen, P. Cao, G. Wen, N. Edmonds, Y. Li, Using an agar-based binder to produce porous NiTi alloys by metal injection moulding, Intermetallics 37 (2013) 92-99

[9] L. Krone, E. Schüller, M. Bram, O. Hamed, H.P. Buchkremer, D. Stöver. Mechanical Behaviour of NiTi parts prepared by powder metallurgical methods, Materials Science and Engineering, Vol A378 (2004) 185-190

[10] L. Krone, J. Mentz, M. Bram, H. P. Buchkremer, D. Stöver, M. Wagner, G. Eggeler, D. Christ, S. Reese, D. Bogdanski, M. Köller, S. A. Esenwein, G. Muhr, O. Prymak, M. Epple. The potential of powder metallurgy for the fabrication of biomaterials on the basis of nickeltitanium: A case study with a staple showing shape memory behaviour, Advanced Engineering Materials, Vol 7, No 7, (2005) 613-619

[11] M. Bram, M. Bitzer, H.P. Buchkremer, D. Stöver. Reproducibility study of NiTi parts made by Metal Injection Molding, Journal of Materials Engineering and Performance (2012) DOI: $10.1007 / \mathrm{s} 11665-012-0264-6$ 
[12] E. Schüller, L. Krone, M. Bram, H. P. Buchkremer, D. Stöver, Journal of Materials Science, 40 (2005) pp.4231-4238

[13] J. Mentz, M. Bram, H.P. Buchkremer, D. Stoever, Improvement of mechanical properties of powder metallurgical NiTi reduction of impurity phases, Proc. of the International Conference on Shape memory and superelastic technologies, Pacific Grove, USA (2006) 399-407

[14] T. Saburi, Ti-Ni shape memory alloys, in Shape memory materials, Eds. K. Otsuka, C. M. Wayman, Cambridge University Press, Cambridge, 1998, 49-96

[15] Y. Shugo, S. Hanada, T. Honma, Effect of oxygen content on the martensite transformation and determination of defect structure in TiNi alloys, Bull. Res. Inst. Miner. Dress. Metall., 41 (1985) 23-34

[16] R. Pelton, J. DiCello, S. Miyazaki, Optimisation of processing and properties of medical grade Nitinol wire, Min. Invas. Ther. \& Allied Technol., 9 (1) (2000) 107-118

[17] K. Otsuka, Introduction to the R-phase transition, in Engineering aspects of shape-memory alloys, T. W. Duerig, K. N. Melton, D. Stöckel, C. M. Wayman (Eds.), ButterworthHeinemann Ltd, London, 1990, 36-45

[18] T. Goryczka, M. Morawiec, Structure studies of the R-phase using X-ray diffraction methods, Journal of Alloys and Compounds, 367 (2004) 137-141

[19] H. Hosoda, T. Inamura, Mechanical properties of shape memory alloys, in Shape memory alloys for biomedical applications, Eds. T. Yoneyma, S. Miyazaki, Woodhead Publishing Limited, Cambridge, 2009, 20-36 